An International Journal of Gastroenterology and Hepatology

\title{
The Manitoba IBD Cohort Study: A prospective longitudinal evaluation of the use of complementary and alternative medicine services and products
}

\begin{tabular}{|c|c|}
\hline Journal: & Gut \\
\hline Manuscript ID: & gutjnl-2011-300219 \\
\hline Article Type: & Paper \\
\hline $\begin{array}{r}\text { Date Submitted by the } \\
\text { Author: }\end{array}$ & 06-Apr-2011 \\
\hline Complete List of Authors: & $\begin{array}{l}\text { Rawsthorne, Patricia; University of Manitoba, Internal Medicine } \\
\text { Clara, Ian; University of Manitoba, Clinical Health Psychology } \\
\text { Graff, Lesley; University of Manitoba, Clinical Health Psychology } \\
\text { Walker, John; University of Manitoba, Clinical health Psychology } \\
\text { Bernstein, Kylie; University of Manitoba, Internal Medicine } \\
\text { Carr, Rachel; University of Manitoba, Community Health Sciences } \\
\text { Ediger, Jason; University of Manitoba, Clinical Health Psychology } \\
\text { Rogala, Linda; University of Manitoba, Internal Medicine } \\
\text { Miller, Norine; University of Manitoba, Internal Medicine } \\
\text { Bernstein, Charles; University of Manitoba }\end{array}$ \\
\hline Keywords: & $\begin{array}{l}\text { ALTERNATIVE MEDICINE, CROHN'S DISEASE, INFLAMMATORY } \\
\text { BOWEL DISEASE, ULCERATIVE COLITIS }\end{array}$ \\
\hline
\end{tabular}

\section{SCHOLARONE ${ }^{\text {M }}$ Manuscripts}


The Manitoba IBD Cohort Study: A prospective longitudinal evaluation of the use of complementary and alternative medicine services and products

Patricia Rawsthorne $\mathrm{RN}^{1,2}$, Ian Clara $\mathrm{PhD}^{1}$, Lesley A Graff $\mathrm{PhD}^{1,3}$, John R Walker $\mathrm{PhD}^{1,3}$, Kylie I Bernstein BSc ${ }^{1}$, Rachel Carr BA ${ }^{1}$, Jason EdigerPhD ${ }^{1,3}$, Linda Rogala $\mathrm{RN}^{1,2}$, Norine Miller $\mathrm{RN}^{1,2}$, Charles $\mathrm{N}$ Bernstein $\mathrm{MD}^{1,2}$

University of Manitoba IBD Clinical and Research Centre ${ }^{1}$ and Departments of Internal Medicine $^{2}$ and Clinical Health Psychology ${ }^{3}$, Winnipeg, Manitoba, Canada Author contributions

Patricia Rawsthorne: study concept and design; analysis and interpretation of data; drafting of the manuscript; critical revision of the manuscript for important intellectual content; statistical analysis

Ian Clara: study concept and design; analysis and interpretation of data; critical revision of the manuscript for important intellectual content; statistical analysis Lesley Graff: study concept and design; analysis and interpretation of data; critical revision of the manuscript for important intellectual content; statistical analysis Kylie I Bernstein: acquisition of the data; critical revision of the manuscript for important intellectual content Rachel Carr: acquisition of the data; critical revision of the manuscript for important intellectual content

John Walker: study concept and design; analysis and interpretation of data; critical revision of the manuscript for important intellectual content; statistical analysis; study supervision Jason Ediger: analysis and interpretation of data; critical revision of the manuscript for important intellectual content

Linda Rogala: acquisition of data; critical revision of the manuscript for important intellectual content; technical, or material support Norine Miller: acquisition of data; critical revision of the manuscript for important intellectual content; technical, or material support

Charles Bernstein: study concept and design; acquisition of data; analysis and interpretation of data; critical revision of the manuscript for important intellectual content; statistical analysis; obtained funding; technical, or material support; study supervision

\section{Funding source}

The study was funded by the Canadian Institutes of Health Research

The Corresponding Author has the right to grant on behalf of all authors and does grant on behalf of all authors, an exclusive licence (or non-exclusive for government employees) on a worldwide basis to the BMJ Publishing Group Ltd, and its Licensees to permit this article (if accepted) to be published in Gut and any other BMJPGL products and to exploit all subsidiary rights, as set out in our licence. 
Address correspondence to

Charles N Bernstein MD

University of Manitoba

804F-715 McDermot Avenue

Winnipeg, Manitoba, Canada R3E3P4

Telephone: 2047893369

FAX: 2047893972

E mail: cbernst@cc.umanitoba.ca 


\begin{abstract}
Background: We aimed to determine the prevalence of complementary and alternative medicine (CAM) use over time in a population-based cohort of IBD patients.

Methods: The Manitoba IBD Cohort Study is a longitudinal, population-based study of multiple determinants of health outcomes in persons with IBD. Participants completed semi-annual surveys, and annual in-person interviews. Inquiries about use of 12 types of CAM service providers and 13 CAM products, based on items from a national survey, were included at month $0,12,30$ and 54 .
\end{abstract}

Results: Overall, $74 \%$ of respondents used a CAM service or product in the 4.5 year period, with approximately $40 \%$ using some type of CAM at each time point, and $14 \%$ using CAM consistently at every time point. There was a trend for females to use CAM more than males; there was no difference in CAM use between Crohn's disease and UC groups. The most often used CAM services (on average) were massage therapy $(29.8 \%)$ and chiropractic (13.6\%), physiotherapy (3.7\%), acupuncture (3.5\%) and Naturopath /Homeopath (3.5\%). There was a wide range of CAM products used, with Lactobacillus/acidophilus (7.6\%), fish and other oils (5.5\%), glucosamine (3.7\%) and chamomile $(3.5 \%)$ as the most common. On average only $18 \%$ of consumers used CAM for their IBD, so the majority chose it for other issues. There were no differences between CAM users and non-users on psychological variables. Conclusions: Those with IBD commonly try CAM, although very few use these approaches regularly over years. CAM is not usually used by IBD patients for disease management, but clinicians should be aware that many will trial the services and products. 
1

2

3

4

5

6

7

8

9

10

11

12

13

14

15

16

17

18

19

20

21

22

23

24

25

26

27

28

29

30

31

32

33

34

35

36

37

38

39

40

41

42

43

44

45

46

47

48

49

50

51

52

53

54

55

56

57

58

59

60

Rawsthorne $\mathrm{P}$ et al

Keywords: Complementary and alternative medicine, cohort study, inflammatory bowel disease

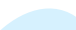


Summary box

What is already known about this subject

1. Complementary and alternative medicine use is common and its use has also been reported as common in patients with inflammatory bowel disease

What are the new findings

1. This was a prospective longitudinal study of a population based cohort of persons with IBD where CAM use could be tracked across 54 months and was measured at four distinct points in time

2.Overall, $74 \%$ of respondents used a CAM service or product in the 4.5 year period, with approximately $40 \%$ using some type of CAM at each time point, and $14 \%$ using CAM consistently at every time point.

3. There was a trend for females to use CAM more than males; there was no difference in CAM use between Crohn's disease and UC. There were no differences between CAM users and non-users on psychological variables.

4. The most often used CAM services (on average) were massage therapy (30\%) and chiropractic (14\%), physiotherapy (4\%), acupuncture (4\%) and Naturopath /Homeopath (4\%). There was a wide range of CAM products used, with Lactobacillus/acidophilus (8\%), fish and other oils (6\%), glucosamine (4\%) and chamomile (4\%) as the most common.

5. On average only $18 \%$ of consumers used CAM for their IBD, so the majority chose it for other issues. 
How might it impact on clinical practice in the foreseeable future?

1. Clinicians should be aware that while patients with IBD are not usually using CAM for disease management, CAM is commonly tried among this group. Hence, clinicians should be familiar with the many services and products available and be open to discussing their use. 


\title{
Introduction
}

Complementary and alternative medicine (CAM) has been reportedly used by 40 to $50 \%$ of patients with inflammatory bowel disease (IBD) (1-6). All of the studies to date have been cross sectional, and hence it is unknown whether the single sampling reflects more regular long-term use. It is worth further exploring CAM use in IBD since physicians have little knowledge of how these agents may interact with conventional therapies. There has been some attention to reasons for choosing CAM, including dissatisfaction with conventional medication or practitioners $(5,7,8)$, however it has not been established in previous research whether IBD patients are using the CAM products and services specifically for IBD or for other health concerns.

\author{
In this longitudinal study, we aimed to establish the prevalence of CAM use over time, \\ considering both services and products. Participants in the Manitoba IBD Cohort Study, a \\ population-based sample of individuals with Crohn's disease (CD) and ulcerative colitis \\ (UC) early in the disease course, were surveyed at four different time points over a 54 \\ month period. The types of CAM used, the persistence of use, the degree to which CAM \\ was used specifically for IBD related symptoms, and personal variables associated with \\ greater CAM use were all examined.
}

\section{Methods}

Participants 
Rawsthorne $\mathrm{P}$ et al

The Manitoba IBD Cohort Study was initiated in 2002, with participating individuals in their $18^{\text {th }}$ year or older and diagnosed with IBD within the previous 7 years (mean of 4 years). Participants are surveyed every 6 months and interviewed annually. They were recruited from a validated population-based research registry that has been previously described (9). The Registry identifies and recruits participants based on an administrative definition of IBD from the comprehensive health data base of Manitoba Health, the single insurer that provides health care to all residents in the province. Of all those with IBD in the province, just over half participated in the Registry. The Manitoba IBD Cohort Study was approved by the University of Manitoba Health Research Ethics Board and participants provided written informed consent.

At the time of the Cohort study recruitment, there were 3192 participants in the Research Registry, of which 606 were eligible for this study, given the age and recent disease onset criteria. Approximately $17 \%$ could not be reached and 14\% directly declined to take part. Complete data were obtained in the first contact from 388 of those enrolled, and they have subsequently served as the Cohort, described elsewhere in detail (10). To assess representativeness, cohort participants were compared to all other IBD cases diagnosed in the same time period, using a comprehensive validated data set which includes all those in the province with IBD (the University of Manitoba IBD Epidemiology Database). There were no significant differences on standard demographic comparisons including mean age, age distribution, sex, urban vs rural residence, and mean duration of disease, suggesting excellent representativeness (11). 
Participants were surveyed at four time points; baseline (Month 0), and Months 12, 30, and 54. CAM use, disease activity, quality of life, perceived stress, and general distress were measured in all four periods. Other factors were measured 1-2 times in the period to reduce participant burden. Demographics and personality factors were assessed at Month 0. Lifetime history of psychiatric diagnoses was assessed at Month 24. Two additional measures of psychological functioning, mastery and health anxiety were assessed at Months 0 and 12, and medication adherence and beliefs were assessed as Month 12.

For this substudy on CAM, 330 of the 388 initial enrollees completed data collection at all 4 survey points of Months 0,12, 30 and 54. Of those 330 participants, 309 provided data on CAM use at all four time points, so they served as the final sample. At Month 0 , participants completed demographic questions regarding marital status, income, education, surgery prior to enrolment and duration of disease diagnosis.

Assessment of CAM use: Questions regarding use of CAM were drawn from a national health survey, the Canadian Community Health Survey (12). Following a series of questions concerning the use of conventional health service providers (e.g., physicians, dentists), participants completed questions about their use of specific alternative medicine services based on the list from the national study, and were also asked whether the use of each was specifically in relation to the IBD or for other reasons. The following questions assessed CAM use: "People may also use alternative or complementary medicine. In the past 12 months, have you seen or talked to an alternative health care provider such as an acupuncturist, homeopath or massage therapist about your physical, 
emotional or mental health?". Twelve categories of CAM service providers were listed and included: massage therapist, acupuncturist, homeopath or naturopath, Feldenkrais or Alexander teacher, relaxation therapist, biofeedback teacher, Rolfer, herbalist, reflexologist, spiritual healer, religious healer, and other. Physiotherapists and chiropractors were some of the more commonly identified providers in the 'other' category. Following a detailed inquiry about conventional prescription and nonprescription medication use, participants were also asked about their use of "other health products such as herbs, minerals or homeopathic products in the past 12 months", and provided with a list of 13 categories of CAM products. These included St. John's Wort/millepertuis, valerian, chamomile, ginseng, Kava Kava/Kava root/ piper methysticum, lavender, chasteberry/chaste tree berries/vitex agnus-castus, black vohash, ginkgo biloba, New Recover-DA, lactobacillus acidophilus, vitamins, and other, where additional products could be listed (e.g., herbal tea, fish and other oils, echinacea, glucosamine).

\section{Disease activity. The Manitoba Inflammatory Bowel Disease Index (MIBDI)}

characterizes symptomatic disease activity over the prior six months, based on 6 levels of symptom frequency in that time period. It has been validated with other clinical indices for CD and UC (13). Participant responses are classified as 'active disease' if any of levels 1-4 were endorsed (e.g. daily to occasional symptoms over six months) and as 'inactive disease' if levels 5-6 were endorsed (e.g., symptoms rare or was completely well). 
Quality of life. The Inflammatory Bowel Disease Questionnaire (IBDQ) is the most widely-used health-related quality of life measure in adult patients with UC and CD. It is a valid and reliable tool, and correlates highly with disease activity (14). The questionnaire consists of 32 questions scored in four domains: bowel symptoms, emotional health, systemic systems, and social function.

Psychological variables. Personality characteristics were assessed using the NEO FiveFactor Inventory (NEO-FFI) (15). The NEO-FFI is a well-validated 60-item scale designed to give quick and reliable measures of the five major domains of adult personality. The domains include Neuroticism, Extraversion, Openness to Experience, Agreeableness, and Conscientiousness.

Validated and standardized measures were used to assess psychological functioning related to stress, health anxiety, mastery and general distress. The Cohen Perceived Stress Scale (CPSS) is a 14-item scale used to examine the role of stress in disease, assessing the individual's perception of their stress level rather than particular stressful events (16). Higher scores correspond to higher levels of perceived stress. The Health Anxiety Questionnaire (HAQ) identifies individuals with high levels of concern about their health (17). The scale evaluates worry and health preoccupation, fear of illness and death, reassurance-seeking behaviour, and symptom interference. A total score is typically reported, with higher scores reflecting higher health anxiety. The 7-item Mastery Scale (18) assesses an individual's sense of their ability to effect change in their life. This scale has been used in health-related studies and has reasonable internal 
reliability and good construct validity $(18,19)$. General distress was measured using the $\mathrm{K}-10$, a ten-item scale evaluating level of emotional distress used widely in epidemiological studies (20).

Psychiatric diagnoses were determined through a semi-structured clinical interview, the Comprehensive International Diagnostic Interview (CIDI), which identified lifetime prevalence of anxiety, mood disorders and phobias $(21,22)$.

Self-description of usual medication adherence was assessed with a validated self-report measure, the Medication Adherence Report Scale (MARS; 23, 25), while the Beliefs About Medication Questionnaire (BMQ, 24, 25) was used to assess beliefs. The BMQ is a 17-item standardized scale with four subscales assessing specific concerns about the medication the person is taking for their disease (Concerns subscale) and beliefs about the importance of that medication to the person's health (Necessity subscale). It also assesses beliefs in general about the potential of medication to produce harm (Harm subscale) and overuse of medications (Overuse subscale). Psychometric data suggest that this measure is both reliable and valid in a variety of medical populations including those being treated for asthma, diabetes, cardiac problems, and psychiatric disorders (32).

\begin{abstract}
Use of prescription medications was assessed for the 6 months prior to each evaluated period, including non-prescription medications such as aspirin, acetaminophen, vitamins and over-the-counter medications, herbal remedies, or dietary supplements.
\end{abstract}




\section{Statistical analysis}

In the first set of analyses, respondents were classified as CAM users and CAM nonusers. The CAM user group included those respondents who reported using any CAM service or product across any of the four assessment points; the CAM non-user group were those who did not use any CAM service or product across any of the four assessment points. Cross-tabulations and chi-square statistics were used to compare group differences for categorical variables. The second set of analyses examined the associations of being a CAM user or non-user with psychological, quality of life, and select demographic variables, at each assessment point individually. To categorize respondents into either a current CAM user or non-user at each respective assessment point, their response on the use of CAM services or products at that assessment point was used. For this analysis, independent-group t-tests comparing current CAM users and nonusers were utilized to assess mean differences of CAM use groups with the continuous psychological and medication adherence at each assessment point. Note that not every psychological measure was administered at each assessment point.

In the final set of analyses, respondents were classified at baseline and again at the end of this study (Month 54) according to their current CAM use at that point (i.e., CAM user / non-user), with a further breakdown of use into one of four mutually exclusive categories: (a) did not use any CAM service or product, (b) used a CAM service only (c) used a CAM product only, and (d) used both CAM services and products. A series of bivariate logistic and multinomial logistic regressions were used to assess the association of type of CAM usage with background (sex, age, education level, disease activity, 
history of surgery), psychological (distress, personality, quality of life, and perceived stress), and medication (prednisone, remicade, immunosuppressants, 5-ASA) variables. Separate regression models were run for each of the two assessment points.

\section{Results}

In this sample, $59 \%$ were female, and the mean age was 40.1 years (range 17-83 yrs). The majority of participants were Caucasian (89\%), 66\% were working full or part-time, and $68 \%$ were married or living common law. Disease type was verified through chart review, and 52\% had Crohn's disease.

\section{Overall Characteristics of CAM Users and Non-Users}

Overall, 74\% $(n=229)$ reported using any type of CAM product or service at some point across the four assessment periods; $26 \%(\mathrm{n}=80)$ reported not using any CAM services or products, and $14 \%$ were persistent users across all 4 time points. Table 1 provides demographic information on CAM users and non-users. Comparing the two groups, the non-users were somewhat older at diagnosis, with $25.3 \%$ vs $14.5 \%$ being over 50 years of age respectively. There were no significant differences in background characteristics or baseline clinical variables between the two groups, including disease type, prior hospitalization, or disease activity. Women were significantly more likely to use CAM services or products than men at a ratio of 2:1 at almost all the assessment periods (Month $12\left(\chi^{2}(1)=4.9, p<0.05\right), 30\left(\chi^{2}(1)=12.6, p<0.01\right)$, and $54\left(\chi^{2}(1)=7.3, p<\right.$ $0.01)$. 
A separate analysis compared the CAM users and non-users for the presence of a lifetime psychiatric diagnosis for the following disorders: specific phobia, social anxiety disorder, agoraphobia, generalized anxiety disorder and major depression. The only significant association between use of CAM and the presence of a lifetime disorder was for lifetime major depression $\left(\chi^{2}(1)=5.4, p<0.05\right)$, with $32 \%$ of CAM users meeting criteria for major depression (versus $18 \%$ of CAM non-users).

\section{CAM service and product use}

Table 2 provides an examination of CAM usage across the four assessment points. At any one time there were at least $40 \%$ of the IBD cohort using some form of CAM services or products, with similar proportions of UC and CD participants using CAM at each time point. Respondents were significantly more likely to use CAM services than CAM products at each of the four assessment points (Month $0: \chi^{2}(1)=12.9, p<0.01$; Month 12: $\chi^{2}(1)=10.8, p<0.01$; Month 30: $\chi^{2}(1)=4.4, p<0.05$; Month 54: $\chi^{2}(1)=$ $12.5, p<0.01)$. There were no significant differences between $\mathrm{CD}$ and UC groups on CAM usage across the four assessment points.

Table 3 describes the most commonly used CAM services and products. The most frequently used CAM services across the four survey periods were: massage therapy (30\%), chiropractor (14\%), and physiotherapy (4\%). While none of the CAM products were used commonly overall, the most frequently used products in this sample were Lactobacillus/acidophilus (8\%), fish and other oils (6\%), and glucosamine (4\%). 
Rawsthorne P et al

Those who identified any use of CAM services or products $(n=229)$ were asked to indicate whether CAM was used specifically for IBD or for other reasons. Across the four assessment points the prevalence of CAM usage (either services or products) for IBD ranged from 14 to $21 \%$. Considering the small subset which just used CAM services (and no CAM products) at any point in the 4.5 years (average $n=19$ ), the average prevalence of use for IBD was $20 \%$ (range from 15 to $24 \%$ ); for the subset which just used CAM products (and no CAM services) (average $n=24$ ) the average prevalence of use for IBD was $46 \%$ (range from $41-52 \%$ ).

\section{Mean Comparisons on Psychological and Quality of Life Variables}

Table 4 presents mean comparisons of psychosocial variables and medication adherence and beliefs for current CAM users and current CAM nonusers, with current users and nonusers defined as those using any CAM product or service at each assessment point. For example, participants were categorized as current CAM users or non-users specifically at month 12 and then compared on variables collected at month 12 . These more time-specific categorizations as a current CAM user or nonuser were used to help determine more immediate temporal relations since CAM use was variable across time for participants.

\footnotetext{
Considering CAM use across the four assessment points, there were almost no significant differences across the psychological and quality of life variables between CAM users and non-users. The only exception to this was a slightly lower level of concern about
} 
overuse of medications among those with no CAM use at Month $12(\mathrm{p}<0.03)$, although this finding should be interpreted with caution given the multiple comparisons.

\title{
Predicting CAM Usage Type at baseline and Month 54
}

The final set of analyses involved both logistic and multinomial logistic regression models to determine the predictive associations of any of the sociodemographic and psychological variables with CAM usage. The first set of models, utilizing logistic regression, had Month 54 current CAM user / non-user as the outcome variable. For predicting Month 54 current CAM users and non-users, all Month 0 sociodemographics and medication variables were used as predictors. As well medication information and disease activity information from the Month 54 assessment was included. In this model, CAM usage at Month 54 was significantly associated with being a CAM User at Month 0 (OR: 2.6, 95\% CI: 1.4-5.1), as was being employed full time (vs not working, OR: 2.6, 1.2-6.1) or being a student (vs not working, OR: 6.0, 1.5-23.7).

\begin{abstract}
A final model examined was a multinomial logistic regression with CAM usage at Month 54, considering four levels of use (current CAM non-user, used CAM services only, used CAM products only, used both CAM services and products) as the outcome variable. Baseline sociodemographic and clinical variables as well as the Medications Beliefs Overuse subscale were included as predictors (the latter as it was the only significant psychological variable in univariate comparisons between current CAM users and nonusers (see Table 4). The following predictors were significant for the following comparisons with 'current CAM non-user' as the reference group: Both CAM services
\end{abstract}


and products: CAM user at Month 0 (OR 9.1, 2.9-28.3), being female (4.2, 1.3-13.9), being a student (13.1, 1.6-108.7); CAM services only: active disease at Month 0 (2.5, 1.0-6.0); CAM products only: no variables emerged as significant.

\section{Discussion}

While CAM use in IBD has been previously studied in our centre and in several other centres worldwide there are a number of unique aspects to this study that help to frame an understanding of the type of person with IBD most likely to use CAM. The current study is population based and encompasses a homogeneous group of IBD patients, in that they have all been diagnosed within 7 years at study entry. They were not specifically recruited through presentation at a referral clinic, reflecting more of a community IBD sample. A major advantage of this study is the longitudinal tracking of CAM use over time, providing insight into the variability or stability of CAM use. Few studies have done this in general, and none with an IBD sample. This is of particular interest in the area of CAM, since some types of CAM may be considered fads and clinicians may have concerns when patients either mix conventional and CAM therapy or exclusively choose CAM $(26,27)$. Finally, this study included a comprehensive assessment of predictors of CAM use including background, clinical and psychological variables.

As part of an international (Winnipeg, Los Angeles, Cork, Stockholm) assessment of CAM use in IBD, prior work by our group found that on average $51 \%$ used some form of CAM. (1). Those more likely to use CAM tended to be single, have a higher income and live in urban areas. A subsequent study considering CAM use and use of conventional 
health care resources (28) found that CAM use was not predicted by either greater or less hospitalizations, physician visits, or gastroenterology-specific physician visits. CAM use was described as primarily to palliate pain $(64 \%)$ or diarrhea $(60 \%)$. However, in that study more general health behaviors such as exercise, diet and prayer were included among the types of CAM, and accounted for the greatest CAM use. There has been some question whether those types of self-care are appropriate to include in CAM definitions (29). In the current study, we used a more focussed CAM definition, based on the range of CAM services and products investigated by the Canadian Community Health Survey requiring that one obtain particular services or products, rather than just engage in different behaviors (12). Using this more specific definition of CAM, we found that most individuals were using CAM for non-IBD related reasons. This may be particularly relevant in clinical practice, as the IBD patient may not think to discuss CAM products they are using with their family physician or gastroenterologist since they are not typically taking them for the IBD, even though they may have an effect on their disease.

Using a different study methodology, another Canadian research group undertook a postal survey of 2847 IBD patient members of the Crohn's and Colitis Foundation of Canada (2). Current or past use of CAM was reported by $47 \%$, of whom $50 \%$ continued their use of CAM (23\% of overall respondents had persistent CAM use). CAM Services were used by $34 \%$, while the most common CAM products used were herbal therapies $(41 \%)$. There was a much larger proportion reporting use of CAM products in this community survey than for the current study. It is possible that the differences in findings reflect differences in recruitment between these surveys. The postal survey 
Rawsthorne P et al

focused primarily on CAM use, which may have drawn those who with an interest in or experience with CAM. In our cohort study, CAM use was embedded in a broader measurement of a range of experiences with IBD.

Similar to previous findings, in our study the majority of those with IBD try CAM (74\%) at some time, but very few, only $14 \%$, were found to use the products and/or services consistently over several years. In considering personal and disease characteristics that might be associated with CAM use, women were more likely to use CAM, as sex differences were found at 3 of 4 assessment points. Three other Canadian studies have reported that CAM use is greater among those with higher education and higher incomes, both for those with and without IBD (31-33). Being female $(8,34,35)$, higher education (30, 31-37), higher income (34-36) and being employed (36) have also correlated with CAM use in the US $(31,35,37)$, Germany (4) and Australia (36). Similar to our findings with a community-based IBD sample, others also have not found CAM use to be associated with disease activity, disease duration, health care utilization or treatments in $\operatorname{IBD}(31)$.

Psychological functioning has not typically been assessed in IBD studies of CAM use so there is little known about any relationships. An American study did report a strong correlation with CAM use when anxiety was present $(\mathrm{OR}=3.1 ; 95 \% \mathrm{CI}, 1.6-6.0)$ and for patients with higher depression and distress scores (29). We found an association between a lifetime diagnosis of major depression and CAM use. Beliefs and attitudes toward CAM have been examined as predictors of use, and views such as contribution to 
personal control of the disease and concerns about conventional therapies have been found to be quite relevant (7).

No single CAM product was used very commonly in this community-based study. The most often used CAM services were massage therapy (29.8\%) and chiropractor (13.6\%). Certainly the distribution of CAM services and products differs widely internationally. Herbal therapies were the most common CAM used by gastroenterology patients attending a UK clinic (43\%) (3). In the German postal survey study of IBD patients, homeopathy $(52.9 \%)$ and herbal medicine (43.6\%) were the most commonly used types of CAM (4). In a French postal survey of IBD patients, only $21 \%$ reported using CAM and the most frequently used CAM were homeopathy (40.6\%), magnetism $(34.8 \%)$ and acupuncture (33.3\%) (8). In a Swiss study of 144 patients, $47 \%$ reported using CAM (5) where the most common CAM used were homeopathy, acupuncture and traditional Chinese medicine (5). In an Australian general population phone survey the most popular CAM were nutritional supplements, massage therapy, meditation, herbal therapy and aromatherapy (33). These variations likely reflect local cultural influences of CAM in different jurisdictions, suggesting that a uniform profile of CAM service or product use worldwide is unlikely. As well, accessibility and availability can vary significantly depending on rural or urban locale, and financial considerations such as extended health insurance coverage. More direct comparisons of population usage and availability of these types of CAM products and services within particular regions would help to provide a context for the level of usage in the IBD community sample. 
Rawsthorne P et al

While the community-based IBD sample, and the longitudinal tracking of CAM use were particular strengths of the study, there were limitations as well. There was reliance on recall of CAM use for the prior 12 month period. The list of services and products from the Canadian census survey provided some recognition prompts for CAM, but it was not an exhaustive list and participants may not have realized other products or services they were using could also be included. As well, the time points where use was assessed were snapshots in time, and there is no way of knowing the frequency or duration of use, except as an approximation across time. Finally, we recognize as discussed about there may be geographic and cultural aspects that impact on what types of CAM services or products are used and hence these data may not be applicable outside of Manitoba or perhaps Canada.

\section{Conclusions}

Almost three-quarters of those with IBD in a community sample tried some form of CAM over a 4.5 year time span, with only $14 \%$ remaining consistent users in that time period.. The minority, around $18 \%$, used any of the products or services specifically for IBD, so 4 out of 5 with IBD are using the products for other reasons. Since its use is so common, clinicians need to make an effort to understand why their patients may choose CAM, where they feel it benefits them, and work with their patients to consider whether there may be any adverse interactions with the management they are prescribing.

However, as few patients remain persistent users over time, clinicians need to be aware that CAM use by patients whether a service or a product, will likely be transient. 
Rawsthorne P et al

\section{Acknowledgments}

Dr. Bernstein is supported in part by a Research Scientist Award of the Crohn's and Colitis Foundation of Canada and the Bingham Chair in Gastroenterology. In the past year Dr. Bernstein has consulted to Abbott Canada and Astra Zeneca Canada and Janssen Canada and received an unrestricted educational grant from AxcanPharma and a research grant from Abbott Canada. This study was supported by a grant from the Canadian Institutes of Health Research. The other authors report no potential conflicts of interest. 
Rawsthorne $\mathrm{P}$ et al

Table 1. Comparison of CAM users (at any of the assessment points) and CAM non-users on demographic and baseline clinical information

\begin{tabular}{|c|c|c|c|}
\hline & & $\begin{array}{l}\text { CAM } \\
\text { users }\end{array}$ & $\begin{array}{l}\text { CAM } \\
\text { non-users }\end{array}$ \\
\hline \multirow[t]{2}{*}{ Sex } & Male & $35 \%$ & $45 \%$ \\
\hline & Female & $65 \%$ & $55 \%$ \\
\hline \multirow[t]{3}{*}{ Age distribution } & $<30$ years & $31 \%$ & $25 \%$ \\
\hline & $31-50$ years & $46 \%$ & $41 \%$ \\
\hline & $>51$ years & $24 \%$ & $34 \%$ \\
\hline Age in years & $\begin{array}{l}\text { Mean years (standard } \\
\text { deviation) }\end{array}$ & $40.1(14.3)$ & $43.4(15.7)$ \\
\hline \multirow[t]{4}{*}{ Employment } & Full / part time & $68 \%$ & $58 \%$ \\
\hline & Student & $11 \%$ & $14 \%$ \\
\hline & $\begin{array}{l}\text { Not working } \\
\text { (homemaker/retired) }\end{array}$ & $14 \%$ & $25 \%$ \\
\hline & Other & $7 \%$ & $3 \%$ \\
\hline \multirow[t]{3}{*}{ Education } & No post secondary & $36 \%$ & $41 \%$ \\
\hline & $\begin{array}{l}\text { Some post-secondary } \\
\text { (trade/diploma) }\end{array}$ & $41 \%$ & $34 \%$ \\
\hline & University & $24 \%$ & $24 \%$ \\
\hline $\begin{array}{l}\text { Income ( dollars per } \\
\text { year) }\end{array}$ & Less than $\$ 40,000$ & $25 \%$ & $29 \%$ \\
\hline
\end{tabular}




\begin{tabular}{|l|l|l|l|}
\hline & $\$ 40-59,000$ & $29 \%$ & $22 \%$ \\
\hline & $\$ 60-79,000$ & $22 \%$ & $24 \%$ \\
\hline Disease type & $\$ 80,000$ or more & $24 \%$ & $24 \%$ \\
\hline & Crohn's disease & $51 \%$ & $57 \%$ \\
\hline Hospitalized for IBD & Yes & $49 \%$ & $43 \%$ \\
\hline Prior surgery & Yes & $57 \%$ & $51 \%$ \\
\hline
\end{tabular}

Note: Chi-square comparisons indicated that none of the variables were significantly different between CAM users and non-users (except for sex (female) at 3 of 4 assessment time points-see text for details). 
Rawsthorne $\mathrm{P}$ et al

Table 2.Percentage of complementary and alternative medicine (CAM) usage across time for the total sample, disease subtypes, and gender.

\begin{tabular}{|l|c|c|c|c|}
\cline { 2 - 4 } \multicolumn{1}{l|}{} & Month 0 & Month 12 & Month 30 & Month 54 \\
\hline Total sample use n=309 & & & & \\
\hline CAM services only & $21 \%$ & $25 \%$ & $18 \%$ & $25 \%$ \\
\hline CAM products only & $11 \%$ & $10 \%$ & $11 \%$ & $9 \%$ \\
\hline Both CAM services and products & $10 \%$ & $14 \%$ & $11 \%$ & $13 \%$ \\
\hline Any CAM service/product & $42 \%$ & $49 \%$ & $43 \%$ & $49 \%$ \\
\hline Disease subtypes and any CAM use & & & & \\
\hline Crohn's disease n=151 & & & & \\
\hline Ulcerative colitis n=136 & $20 \%$ & $26 \%$ & $25 \%$ & $27 \%$ \\
\hline Gender and any CAM use & & & & \\
\hline Males n=116 & & & & \\
\hline Females n=193 & & & & \\
\hline
\end{tabular}


Table 3: Proportion of CAM users ( $n=229)$ using five most frequently used CAM services and products across the four contact points

\begin{tabular}{|c|c|c|c|c|}
\hline & Month 0 & Month 12 & Month 30 & Month 54 \\
\hline \multicolumn{5}{|l|}{ CAM services } \\
\hline Massage therapy & $19 \%$ & $35 \%$ & $27 \%$ & $38 \%$ \\
\hline Chiropractor & $19 \%$ & $22 \%$ & $5 \%$ & $9 \%$ \\
\hline Physiotherapy & $8 \%$ & $0 \%$ & $3 \%$ & $4 \%$ \\
\hline Acupuncture & $1 \%$ & $6 \%$ & $2 \%$ & $5 \%$ \\
\hline Homeopath/naturopath & $2 \%$ & $6 \%$ & $3 \%$ & $4 \%$ \\
\hline \multicolumn{5}{|l|}{ CAM products } \\
\hline Lactobacillus acidophilus & $4 \%$ & $6 \%$ & $12 \%$ & $8 \%$ \\
\hline Chamomile & $0 \%$ & $2 \%$ & $7 \%$ & $6 \%$ \\
\hline Fish and other oils & $6 \%$ & $8 \%$ & $4 \%$ & $4 \%$ \\
\hline Glucosamine & $4 \%$ & $5 \%$ & $2 \%$ & $4 \%$ \\
\hline Echinacea & $3 \%$ & $4 \%$ & $0 \%$ & $0 \%$ \\
\hline \multicolumn{5}{|l|}{ IBD-related use: } \\
\hline Any CAM service/product & N/A ${ }^{1}$ & $14 \%$ & $21 \%$ & $18 \%$ \\
\hline
\end{tabular}

${ }^{1}$ Reason for CAM use (for IBD or for nonIBD condition) was not asked at Month 0 
Table 4. Mean scores on psychological and quality of life variables comparing current CAM users and nonusers at each contact point

\begin{tabular}{|c|c|c|c|}
\hline 8 & $\begin{array}{l}\text { CAM } \\
\text { Current User } \\
\text { Mean (SD) }\end{array}$ & $\begin{array}{l}\text { CAM } \\
\text { Current Non-user } \\
\text { Mean (SD) }\end{array}$ & $\begin{array}{l}p \text {-value } \\
(t \text {-test })\end{array}$ \\
\hline Years since diagnosis & $4.3(2.2)$ & $4.3(2.0)$ & 0.95 \\
\hline Month 0 & Users $(n=132)$ & Nonusers $(n=198)$ & \\
\hline${ }^{\mathrm{T}}$ Neuroticism & $20.7(7.4)$ & $20.1(7.8)$ & 0.50 \\
\hline${ }^{1}$ Openness & $26.0(5.8)$ & $25.0(5.0)$ & 0.12 \\
\hline${ }^{1}$ Extraversion & $25.4(5.7)$ & $24.7(5.4)$ & 0.27 \\
\hline${ }^{1}$ Agreeableness & $32.7(5.1)$ & $31.9(5.7)$ & 0.23 \\
\hline${ }^{1}$ Conscientiousness & $33.0(5.8)$ & $32.5(5.9)$ & 0.51 \\
\hline Perceived stress & $22.2(7.6)$ & $22.3(8.6)$ & 0.89 \\
\hline Health anxiety & $15.3(9.5)$ & $14.0(9.2)$ & 0.23 \\
\hline Mastery & $19.2(4.5)$ & $19.3(4.4)$ & 0.86 \\
\hline IBD Quality of life & $164.1(30.0)$ & $167.1(32.9)$ & 0.41 \\
\hline Month 12 & Users $(n=155)$ & Nonusers $(n=175)$ & \\
\hline Perceived stress & $21.0(8.2)$ & $21.1(8.3)$ & 0.93 \\
\hline Health anxiety & $12.4(8.5)$ & $13.0(9.3)$ & 0.52 \\
\hline Mastery & $19.4(4.9)$ & $19.1(4.6)$ & 0.53 \\
\hline Medication adherence & $20.7(3.9)$ & $21.0(4.0)$ & 0.63 \\
\hline Medication beliefs: Concerns & $13.7(4.1)$ & $13.1(4.3)$ & 0.26 \\
\hline Medication beliefs: Necessity & $15.9(4.8)$ & $16.4(5.4)$ & 0.49 \\
\hline
\end{tabular}




\begin{tabular}{|l|l|l|l|}
\hline Medication beliefs: Overuse & $9.4(2.4)$ & $8.8(2.4)$ & 0.03 \\
\hline Medication beliefs: Harm & $9.5(2.6)$ & $9.9(2.5)$ & 0.22 \\
\hline IBD Quality of life & $172.0(29.8)$ & $172.5(33.2)$ & 0.90 \\
\hline Month 30 & Users (n=159) & Nonusers (n=171) & \\
\hline Perceived stress & $20.7(8.2)$ & $20.5(8.8)$ & 0.91 \\
\hline IBD Quality of life & $178.0(26.5)$ & $177.3(27.8)$ & 0.84 \\
\hline Month 54 & Users (n=172) & Users (n=158) & \\
\hline Perceived stress & $19.4(9.2)$ & $19.8(9.2)$ & 0.71 \\
\hline IBD Quality of life & $176.7(28.7)$ & $177.3(28.4)$ & 0.73 \\
\hline
\end{tabular}

${ }_{\text {I }}$ subscales of NEO-Five Factor Inventory (FFI) personality measure

The NEO-FFI was administered at Month 0. Medication adherence and beliefs about medication were assessed at Month 12 . Health anxiety and mastery were assessed at Months 0 and 12. 
Rawsthorne P et al

\section{REFERENCES}

1.Rawsthorne P, Shanahan F, Cronin NC, Anton PA, Löfberg R, Bohman L, Bernstein $\mathrm{CN}$. An international survey of the use and attitudes regarding alternative medicine by patients with inflammatory bowel disease.Am J Gastroenterol 1999;94(5):1298-303. 2.Hilsden RJ, Verhoef MJ, Best A, Pocobelli G. Complementary and alternative medicine use by Canadian patients with inflammatory bowel disease: results from a national survey.Am J Gastroenterol 2003; 98: 1563-8.

3.Langmead L, Chitnis M, Rampton DS. Use of complementary therapies by patients with IBD may indicate psychosocial distress. Inflamm Bowel Dis. 2002;8:174-9.

4.Langhorst J, Anthonisen IB, Steder-Neukamm U, Amount of systemic steroid medication is a strong predictor for the use of complementary and alternative medicine in patients with inflammatory bowel disease: results from a German national survey. Inflamm Bowel Dis. 2005;11:287-95.

5.Quattropani C, Ausfeld B, Straumann A, Heer P, Seibold F. Complementary alternative medicine in patients with inflammatory bowel disease: use and attitudes.Scand $\mathbf{J}$

Gastroenterol. 2003;38:277-82.

6.Joos S, Rosemann T. Use of complementary and alternative medicine in Germany - a survey of patients with inflammatory bowel disease, BMC Complement Altern Med 2006; 22; 6-19.

7.Li FX, Verhoef MJ, Best A. Why patients with inflammatory bowel disease use or do not use complementary and alternative medicine: a Canadian national survey. Can J Gastroenterol 2005; 19: 567-73 
8.Bensoussan M, Jovenin N, Garcia B, et al. Complementary and alternative medicine use by patients with inflammatory bowel disease: results from a postal survey.

GastroenterolClinBiol 2006; 30: 14-23.

9.Bernstein CN, Blanchard JF, Rawsthorne P, et al. The epidemiology of Crohn's disease and ulcerative colitis in a central Canadian province: a population-based study. Am J Epidemiol 1999;149:916-924.

10.Graff LA, Walker JR, Lix L, et al. The relationship of inflammatory bowel disease type and activity to psychological functioning and quality of life.Clin Gastro Hepatol 2006;4:1491-1501.

11.Longobardi, T, Bernstein, CN. Hearsay: is patient self-report of health care utilization accurate? Gastroenterology 2008;134(suppl 1):A-498.

12. Gravel, R., Béland Y. The Canadian Community Health Survey: Mental health and well-being. Canadian Journal of Psychiatry 2005; 50: 573-579.

13.Clara I, Lix LM, Walker JR, Graff LA, Miller N, Rogala L, Rawsthorne P, Bernstein CN. The Manitoba IBD Index: Evidence for a New and Simple Indicator of IBD Activity. Am J Gastroenterol 2009; 104:1754-63.

14.Guyatt G, Mitchell A, Irvine EJ, Singer J, Williams N, Goodacre R, et al. A new measure of health status for clinical trials in inflammatory bowel disease.

Gastroenterology 1989;96:804-810.

15.McCrae RR, Martin TA, Costa PT Jr. Age trends and age norms for the NEO Personality Inventory-3 in adolescents and adults.Assessment 2005; 12(4):363.

16. Cohen S, Kamarck T, Mermelstein R. A global measure of perceived stress.J Health SocBehav 1983; 24:385-396. 
Rawsthorne P et al

17. Lucock, MP, Morley S. The health anxiety questionnaire. Brit J Health Psychol $1996 ; 1(2): 137-150$.

18. Perlin, LI, Schooler C. The structure of coping. J Health Social Behav 1981; 19: 221.

19. Seeman, T. E Personal control and coronary artery disease: How generalized expectancies about control may influence disease risk. J Psychosom Res 1991; 35: 661669.

20. Kessler, Andrews, Colpe, Hiripi, Mroczek, Normand, Walters, \&Zaslavsky. Short screening scales to monitor populationprevalences and trends in non-specific psychological distress. Psychol Med 2002; 32: 959-976.

21. Composite International Diagnostic Interview. Version 2.1. Geneva, World Health Organization, 1997.

22.Wittchen HU. Reliability and validity studies of the WHO--Composite International Diagnostic Interview (CIDI): a critical review. J Psychiatr Res. 1994; 28:57-84.

23.Horne R, Weinman J. Patients' beliefs about prescribed medicines and their role in adherence to treatment in chronic physical illness. J Psychosom Res 1999;47:555-567.

24. Horne E Weinman J Hankins M. The Beliefs about Medicines Questionnaire: the development and evaluation of a new method for assessing the cognitive representation of medication. Psychol Health 1999 14:1-24

25. Ediger JP, Walker JR, Graff LA, Lix L, Clara I,.Predictors of medication adherence in inflammatory bowel disease. Am J Gastroenterol 2007; 102: 1417-26.

26. Dwyer J. Fertile field for fads and fraud. Questionable nutritional therapies. N Y State J Med 1993;93:105-8. 
27. Braganza SF, Ozuah PO. Fad therapies.Pediatr Rev 2005;26:371-6.

28. Burgmann T, Rawsthorne P, Bernstein CN. Predictors of alternative and complementary medicine use in inflammatory bowel disease: do measures of conventional health care utilization relate to use?Am J Gastroenterol.2004; 99:889-93. 29. Astin JA. Why patients use alternative medicine: results of a national study. JAMA $1998 ; 279: 1548-53$

30. Blais R, Maiga A, Aboubacar A. How Different Are Users and Non-Users of Alternative Medicine? Can J Public Health 1997; 88:159-62.

31. Sirois FM. Provider-based complementary and alternative medicine use among three chronic illness groups: associations with psychosocial factors and concurrent use of conventional health-care services. Complement Ther Med 2008;16:73-80.

32. Ganguli SC, Cawdron R, Irvine EJ. Alternative medicine use by Canadian ambulatory gastroenterology patients: secular trend or epidemic?Am J Gastroenterol 2004;99:31926.

33. Barnes PM, Bloom B. Complementary and Alternative medicine use among adults and children: United States, 2007 National Health Statistics ReportsNatlHealth Stat Report 2008; 10:1-23

34. Xue CC, Zhang AL, Lin V et al. Complementary and Alternative Medicine Use in Australia: A National Population-Based Survey. J Altern Complement Med. 2007; 13:643-50.

35. Eisenberg DM, Kessler RC, Foster C, et al Unconventional medicine in the United States. Prevalence, costs, and patterns of use. N Engl J Med 1993; 328:246-52. 
Rawsthorne P et al

36. Langhorst J, Anthonisen IB, Steder-Neukamm U, Amount of systemic steroid medication is a strong predictor for the use of complementary and alternative medicine in patients with inflammatory bowel disease: results from a German national survey.

Inflamm Bowel Dis 2005;11(3):287-95 